into genetical and statistical sections. Most of the examples used in the book are taken from human genetics. Moreover there are separate chapters devoted to special topics in human genetics such as segregation analysis (simple and complex), human blood groups, linkage analysis, histocompatability testing, and single-locus versus several-loci models. Each chapter has a series of problems for the student but unfortunately no results are given. Despite the size of the book (592 pages) the coverage of the field is not complete and some topics are discussed only briefly. For example the effects of genetic drift and small population size, assortative mating, mutation and selection in evolutionary genetics and the methods of analysis for quantitative traits are some important subjects which are treated rather briefly.

The book is well presented with very few errors, despite its complexity and size. Since much of the material presented is available elsewhere, it may not be an essential book for the statistical geneticist, but it should be a very useful reference text, especially for the statistical human geneticist. I have no hesitation in recommending it to anyone interested in these topics.

Charles Smith

\section{Cytoenzymology and Isozymes of Cultured Cells.}

By P. J. Melnick. Progress in Histochemistry and Cytochemistry, Volume 2, No. 1. (Pp. 77; 30 figs. DM. 44-00.) Stuttgart: Gustav Fischer. 1971.

This short book is essentially two reports of different aspects of the author's recent work on enzymes of cultured cells.

The first part deals with cytoenzymology, which is defined as the application of histochemical techniques to free-living cells. There is a clear description of how the many problems - such as finding conditions in which substrates are able to penetrate cell membranes and yet soluble enzymes and reaction products are prevented from diffusing out-were overcome. Activity in all 28 hydrolytic and oxidative enzymes studied was successfully demonstrated and our attention is drawn to two significant observations: firstly, that the product was almost always seen to be granular. If this is really an indication of the sub-cellular organization of these enzymes as the author speculates, a powerful new tool for the study of activity-structure relationships could become available. And secondly, that the extent of reaction is very variable in different cells of the same preparation. This would also be important if, as is suggested, it was found to correlate with the growth cycle of the cell. Even if these speculations are incorrect and the observations are simply due to the unusual conditions used and the technical difficulties encountered, the author has shown that enzyme activity can be consistently demonstrated in living cells. It is therefore likely that cytoenzymology will eventually become useful in the study of the effect of environmental and other changes on cell enzymes in conditions nearer to physiological than those more commonly used.

Though cytoenzymology may hold some distant promise, the more familiar subject of isoenzyme separations by gel electrophoresis, which is the theme of the second part of this book, is of more direct application. When the isoenzyme patterns for several of the 18 enzymes in each of the 5 cell lines studied are compared, they are seen to be quite different and, therefore, of use in cell line identification. The extension of such studies to many more cell lines will obviously be worthwhile.

This book is recommended to those doing experimental work in the fields discussed but the general reader will want to wait until the promises have been fulfilled.

R. B. ElLIS

Hereditary Sensory Radicular Neuropathy. By David C. Wallace. (Pp. 114; illustrated + tables.) Sydney: Australasian Medical Publishing Company. 1970.

Dr Wallace describes a large Australian family who have the condition where a distal sensory neuropathy, often involving the legs only, is associated with recurrent ulceration of the feet. The dominant form, present in this family, develops after puberty, is only slowly progressive, and is severer in males. As the author points out, the main interest in the family lies in describing the range of clinical manifestation that may result from the same mutant gene. The disorder varies from females who have no symptoms (but where sensory abnormalities will be detected by a medical examiner) to a male, with a distal neuropathy, both sensory and motor, mutilated feet from recurrent ulceration and osteomyelitis, and secondary amyloidosis. Useful radiological and pathological information are also given in this book and genetic data are adequately discussed. However, little that is new is revealed.

SARAH BUNDEY

Chemical Mutagenesis in Mammals and Man. Edited by F. Vogel and G. Röhrborn. (Pp. xiv +519; 95 figures + tables. \$34.10.) Berlin, Heidelberg, and New York: Springer Verlag. 1970.

The induction of mutations following exposure of mammals, or mammalian cells, to chemical agents is a topic of considerable importance; all the more so because of the increasing exposure of our own species to a wide variety of noxious chemical agents in our general environment and to the increasing use (and misuse) of an ever widening variety of pharmacological products. The present volume would therefore appear to be timely, and in their preface, the editors remark that the book is particularly designed for those who are interested in the problem of chemical mutagenesis in relation to man. The aim is laudible. Unfortunately, the execution leaves much to be desired.

The volume in fact contains papers presented at a 
symposium on mutation research held in Mainz in October 1969, supplemented by a number of additional papers and an appendix dealing with statistical methods used in mutation research. The discussions are centred on test methods employed in mutagenicity research with mammals and the contributions are parcelled up into three main sections: three chapters on 'Aspects of the problem'; 15 on 'Research methods'; 11 on 'Findings and applications'. There are some useful review chapters dealing with biochemical mechanisms of mutation, spontaneous mutation rates in man, and lists of chemical substances known to induce mutations in microorganisms and chromosome damage in human cells cultured in vitro. There are also useful papers on host-mediated assay systems in which bacterial cells, fungal spores, or mammalian cells are introduced into a mammalian host before the exposure of the host to a mutagen. The mutagenicity of compounds taken up and metabolized by the host is tested through assaying the mutation frequency in the introduced cells. Hostmediate assay systems of this sort are important tools since some compounds, eg, N-methyl-N-nitro-Nnitrosoguanidine (MNNG), may be powerful mutagens in vitro but appear to be only weakly mutagenic in vivo, whereas others, eg, cyclophosphamide, are much more potent in vivo.

A number of the contributions make very dull reading and like most published symposia, most of what is said has been published previously: the afficionado therefore will find little to whet his appetite. On the other hand the book should provide a useful guide to the interested bystander as to what is happening in this area of science. Unfortunately, the reading is not made any easier by the presence of an excessively large number of errors, many of which are a direct consequence of the fact that the bulk of the papers have been translated into English from the original German. Translational errors are, however, relatively easy to spot, eg, 'Professional exposition' (p. 50) in place of 'professional (occupational ?) exposure', and, in general, do not present the reader with too much difficulty. Of far more importance are the numerous incorrect references; papers referred to in the text but not in the reference lists; and, in one instance, the presence of lengthy, and useful, tables (pp. 370-373) referring to 96 references by number without the corresponding numbers identifying the references listed at the end of the paper. These and other irksome editorial errors detract from the value of the book.

H. JoHN Evans

\section{Papers on Regulation of Gene Activity During} Development. Edited by William F. Loomis. (Pp. ix + 442: figures + tables. £3.15.) New York: Harper and Row. 1970.

This book has been sitting on my desk for too long. My problem is that I have not known how to review it. It is one of those increasing number of books which consists of reprints (by typographically-unfortunate photo- reproduction) of papers published in a variety of places. So how does one comment? Presumably all the papers have been refereed and revised before their original appearance, and to criticize them on their reincarnation seems irrelevant in this context. This means that the only thing to review is the editor's choice of papers.

Loomis has collected 49 papers under five headings: endogenous control of enzyme synthesis in eukaryotic microorganisms; differential synthesis of proteins in developing organs; chromosomal differentiation; control of enzyme content in liver cells; haemopoesis. He justifies his inclusion of the last two apparently specialized and limited groupings (comprising 24 papers) thus: 'since the products of intestinal absorption are carried directly to the liver via the portal vein, cells of this tissue are subject to frequent chemical changes. Thus it seemed logical to look for cases of substrate stimulation of enzyme stimulation in liver cells . . .' and ' . . . the fact that hemoglobin makes up more than 98 per cent of the total protein of a red blood cell makes these cells especially suitable for the study of the regulation of gene activity'. As will be apparent, Loomis is biassed towards that stage of gene activity when the gene products have (presumably although not necessarily demonstrably) function but no obvious form. Twelve of his selected papers come from the Proceedings of the National Academy of Sciences of the United States of America, and a further 19 from assorted biochemical journals. Only one was published in a 'normal' embryological journal (Developmental Biology).

Can one assess the value of this selection? Some of the current accumulations of significant, classic, or wellwritten papers can be extremely useful as sources of concepts and references, or as background reading for students. No doubt the Loomis 49 will be valuable to some. I must confess that my emotion after leafing through the book was of disappointment that the problems of the relationship between gene and character expounded by Goodrich, and studied by Waddington, Dunn, Grüneberg, Landauer, Hadron, GluecksohnWaelsch, Deol, Forsthoefel, and their ilk were not included (the closest any of the 49 come to them is Mary Lyon's Nature paper that earned her a place in the dictionaries as the mother of Lyonization). Perhaps I expected too much from the title (to be fair, I cannot think of a more appropriate one). Or-dare I say itpossibly the pathways of gene activity studied by biochemists do not reach as far as the traits that occur in the obstetrician's and paediatrician's consulting room?

R. J. BERRY

Birth Defects: Original Article Series, VII, 1. Second Conference of the Delineation of Birth Defects, Part VI, 'Nervous System'. (Pp. 255; illustrations. $£ 8.00$.) Baltimore: Williams and Wilkins (and Edinburgh: E. \& S. Livingstone) for The National Foundation-March of Dimes, New York. 1971.

This volume in the Birth Defects series is a valuable review of neurological problems, providing also reports 